\title{
Direct Measurement of Brain Temperature during and after Intraischemic Hypothermia: Correlation with Behavioral, Physiological, and Histological Endpoints
}

\author{
Suzanne Nurse and Dale Corbett \\ Division of Basic Medical Sciences, Faculty of Medicine, Memorial University of Newfoundland, St. John's, NF Canada \\ A1B 3V6
}

The aim of the present study was to evaluate critically the protection afforded by hypothermia against ischemic injury to the hippocampus. Hypothermic treatment was applied selectively to the brain during a 5 min carotid artery occlusion in gerbils. Following a period of recovery, two independent measures were used to assess hippocampal function: (1) an open field test of spatial memory (assessment was made during the first $10 \mathrm{~d}$ after ischemia) and (2) measurement of evoked potentials from area CA1 in hippocampal slices (3 weeks after the ischemic episode). The functional outcome portrayed by these tests was compared to a morphological evaluation of CA1 pyramidal cells at three rostrocaudal levels. All evaluations were carried out in the same animals.

We found converging evidence that intraischemic hypothermia provides virtually complete protection against a 5 min episode of cerebral ischemia. Animals treated with hypothermia performed as well as sham-operated controls in a spatial memory task, had field potentials that were indistinguishable from normal animals and CA1 cells appeared normal when assessed histologically. In contrast, ischemia at normothermia resulted in a deficit in open field behavior $(p<0.01)$, diminished field potentials in stratum radiatum $(p<0.01)$, and near total loss of pyramidal cells in dorsal CA1 ( $p<0.01$ ). There was a remarkably high correlation between these diverse measures ( $r$ ranged from 0.7 to 0.9 , $p<0.01$ ), which provides strong support for the use of hypothermia as an effective treatment for ischemia.

This study introduces a novel approach for the evaluation of putative anti-ischemic treatments: combining behavioral, electrophysiological, and histological measures. Each method of assessment can provide information relating to separate aspects of hippocampal functioning, and when used in combination should yield a more accurate appraisal than any single method.

[Key words: cerebral ischemia, neuroprotection, CA 1, hypothermia, memory, locomotor activity, electrophysiology, EPSP, hippocampal slice]

\footnotetext{
Received Feb. 9, 1994; revised June 7, 1994; accepted June 16, 1994.

Financial support was provided by the Medical Research Council of Canada through a grant awarded to D.C. We express sincere thanks to Suzanne Evans, Dr. Richard Neuman, Dr. Carolyn Harley, and Dr. John Evans for their helpful comments and suggestions during the course of this project.

Correspondence should be addressed to Suzanne Nurse at the above address. Copyright (C) 1994 Society for Neuroscience 0270-6474/94/147726-09\$05.00/0
}

Global cerebral ischemia, a condition that occurs during cardiac arrest, can result in irreversible brain damage, most noticeably in the CAl sector of the hippocampus. In both humans and animal models this necrosis is delayed and, using standard histological procedures such as Nissl stains, is undetectable for 2$4 \mathrm{~d}$ following the ischemic insult and may take at least $7 \mathrm{~d}$ to be complete (Kirino, 1982; Pulsinelli et al., 1982; Horn and Schlote, 1992). IIowever, cell death is preceded by a decay in the evoked response of CA1 pyramidal cells to Schaffer collateral stimulation (Urban et al., 1989, 1990). In hippocampal slices taken from animals that have previously undergone an episode of cerebral ischemia, electrophysiological function can be preserved by intracellular injection of $\mathrm{Ca}^{2+}$ chelators and deterioration is hastened by $\mathrm{IP}_{3}$ activation (Kirino et al., 1992; Tsubokawa et al., 1992). This evidence suggests that the irreversible alteration in electrophysiological response following ischemia is $\mathrm{Ca}^{2+}$ dependent. Abnormal $\mathrm{Ca}^{2+}$ homeostasis is also believed to be the trigger for the subsequent neuronal death (Choi, 1985; Siesjo and Bengtsson, 1989). Thus, deterioration in the evoked response of CA1 neurons to afferent stimulation could be used as an early marker of cell death.

Neuroprotective treatments, such as glutamate antagonists (Warner et al., 1990) or prior lesioning of excitatory inputs (Kaplan et al., 1989), have been reported to preserve CA1 cells histologically for several weeks. However, if these cells are examined using silver impregnation, their appearance is similar to a transition state observed in untreated animals $24-48 \mathrm{hr}$ after ischemia, when electrophysiological function has been lost, though neurons are still considered viable (Warner et al., 1990). Thus, it may be that certain anti-ischemic treatments that have appeared neuroprotective simply slow down cell death by several days or weeks, but do not preserve function. Since most researchers tend to quantify ischemic damage using survival times of 3-7 d, and rely solely on Nissl-stained material, a normal or near-normal appearance does not necessarily reflect preserved function or long-term protection. Consequently, the electrophysiological responsiveness of $\mathrm{CA} 1$ pyramidal cells may be a more sensitive measure of CAl integrity than histological assessment alone, especially in cases where "protective treatments" have been administered.

Cell death resulting from global ischemia can lead to memory deficits in rodents and primates (Zola-Morgan et al., 1986, 1992; Auer et al., 1989; Corbett et al., 1992). Neurobehavioral tests of memory function have been shown to be sensitive indices of hippocampal cell loss resulting from ischemia. Even following mild cases of ischemia, which have not resulted in detectable 
CA1 cell loss, deficits in spatial memory function were evident several days after occlusion (Jaspers et al., 1990). Therefore, it is crucial to combine behavioral testing with histological assessment in order to determine whether putative neuroprotective treatments preserve cognitive functions as well as neurons, since this is the ultimate goal. However, with increasing recovery time memory impairments can be less evident unless more intricate tests are employed. For example, we were able to show a deficit in Morris water maze performance using the simple place learning task starting $3 \mathrm{~d}$, but not 3 weeks, following ischemia (Corbett et al., 1992). Other researchers (Auer et al., 1989; Green et al., 1992) revealed a protracted memory impairment by employing the more difficult place learning-set variation of this task 6-8 weeks after ischemia. Recovery of function has been demonstrated in other memory tests as well (Imamura et al., 1991; Katoh et al., 1992) and is presumably due to compensation by undamaged structures within the hippocampal formation itself or other brain regions. The ability of the nervous system to compensate for neuronal loss can complicate the interpretation of behavioral tests if they are used in isolation.

Since behavioral, electrophysiological, and morphological evaluations can all be used to assess outcome following cerebral ischemia, combining all three should provide a powerful method for gauging the efficacy of a neuroprotective treatment. If each of these measures are reliable indicators of CA1 integrity, and if a treatment strategy has been truly beneficial, then converging evidence for neuroprotection should be obtained.

The objective of the present study was to evaluate the protection afforded by intraischemic hypothermia using the above multi-faceted approach. It is well known that mild to moderate intraischemic hypothermia can provide near total protection of CAl neurons from ischemia (Busto et al., 1987; Chopp et al., 1989; Minamisawa et al., 1990a,b; Welsh et al., 1990; Dietrich et al., 1993; Iwai et al., 1993). Hypothermia has been suggested to be the "gold standard" to which other therapies should be compared (Buchan, 1992); thus, it seemed the best candidate to evaluate the potential benefit of the above functional and histological measures of ischemic injury. Ischemia was induced by occluding the carotid arteries for $5 \mathrm{~min}$ in gerbils, while brain temperature was either maintained at normothermia or lowered to $\sim 30^{\circ} \mathrm{C}$. These groups were compared to sham-operated controls in a novel open field maze, a test that has previously been shown to reflect reliably the extent of CA1 damage (Gerhardt and Boast, 1988; Wang and Corbett, 1990; Mileson and Schwartz, 1991; Babcock et al., 1993). After a 3 week survival period, hippocampal slices were prepared from one hemisphere in order to measure the responsiveness of CA1 neurons to afferent stimulation, while the other hemisphere was retained for histological analysis. Thus, the behavioral, electrophysiological and histological measures were all derived from the same animals.

\section{Materials and Methods}

Animals. Twenty adult female Mongolian gerbils (High Oak Ranch, Goodwood, ON) were used in this study. At the initiation of the experiment, animals were 3.5-6 months of age and ranged in weight from 55 to $90 \mathrm{gm}$. All experimental procedures have been carried out in accordance with the guidelines of the Canadian Council on Animal Care with prior approval of the Animal Care Committee of Memorial University of Newfoundland.

Preparation for brain temperature measurement. Brain temperature was sampled using wireless temperature probes [model XM-FH (8 mm), Mini-Mitter Co., Sunriver, OR; see Colbourne et al., 1993]. Four days prior to ischemia/sham surgery, animals were anesthetized with sodium pentobarbital $(65-70 \mathrm{mg} / \mathrm{kg})$, while a 20 gauge guide cannula $(5 \mathrm{~mm})$ was implanted at the dural surface overlying the dorsomedial striatum (either above the left or right hemisphere). A 27 gauge stylet was inserted in the cannula to prevent contamination by foreign material between periods of brain temperature monitoring. To measure brain temperature, the stylet was removed and the Mini-Mitter probe inserted into the striatum. Two days prior to ischemia/sham surgery, striatal temperature was measured continuously for $3 \mathrm{hr}$ to provide baseline values.

Cerebral ischemia. Anesthesia was induced with $2 \%$ halothane and maintained with $1.5 \%$ halothane in $30 \% \mathrm{O}_{2}$ and $70 \% \mathrm{~N}_{2} \mathrm{O}$. Rectal, skull, and brain temperatures were measured as previously described (Colbourne et al., 1993). Rectal temperature was maintaincd betwecn $37.8^{\circ} \mathrm{C}$ and $38.0^{\circ} \mathrm{C}$ throughout the surgical procedure. Brain temperature was maintained near $37.0^{\circ} \mathrm{C}$ with a separate blanket system (model TP-3E, Gaymar Industries Inc., Orchard Park, NY) heated by a water bath. This blanket was in direct contact with the top and sides of the head in order to distribute heat to the brain as evenly as possible. The common carotid arteries were isolated through a midline incision in the neck and looped with silk suture. After carotid isolation animals were divided into three treatment groups: (1) $5 \mathrm{~min}$ ischemia at normothermic brain temperature (NBT; $n=7),(2) 5 \mathrm{~min}$ ischemia with intraischemic brain hypothermia (IBH; $n=7$ ), and (3) a sham-operated control group, treated comparably to group 1 except for the induction of ischemia (SHAM; $n=6$ ). Cerebral ischemia was induced by placing vascular clamps on the carotid arteries for $5 \mathrm{~min}$. Following clamp removal reflow was confirmed visually and the incision suturcd. Brain tempcraturc was lowered in the IBH group by promptly changing the water source for the head blanket from the heated water bath to an ice bath just as the arteries were being occluded. Once the brain temperature reached $\sim 30.0^{\circ} \mathrm{C}$ the water temperature was adjusted to maintain a steady state. Upon reperfusion, normothermia was restored by reverting to the original water source.

Once brain temperatures returned to the preischemic level ( $5 \mathrm{~min}$ or less in the NBT group, and $\sim 10$ min postocclusion in the IBH group), the skull thermistor and rectal thermometer were removed and anesthesia was discontinued. Duration of the entire surgical procedure was similar in all three groups, approximately $30-35 \mathrm{~min}$. Brain temperature monitoring continued for an additional $3 \mathrm{hr}$ in unrestrained animals, and rectal temperature was sampled twice, 30 and 60 min postischemia. Postischemic brain temperature data for one animal in the sham-operated control group had to be excluded because of irregular readings due to battery failure.

Behavioral testing. Animals were tested in an open field maze $(72 \times$ $76 \times 57 \mathrm{~cm}$ ) to which they had not been exposed before ischemia/sham operations. Testing was carried out in three $10 \mathrm{~min}$ sessions 3,7 , and $10 \mathrm{~d}$ postsurgery. The floor of the maze was divided into 25 squares, and a computerized tracking system counted the total number of squares entered during each trial (see Wang and Corbett, 1990). All behavioral testing was carried out in a soundproofed room $(2.1 \times 3.4 \mathrm{~m})$. Distinctive features of the room and lighting conditions were kept constant for the duration of the experiment.

Hippocampal slice preparation and electrophysiological recording. Twenty-one to twenty-three days following ischemia/sham surgery, animals were anesthetized with $2 \%$ halothane in $30 \% \mathrm{O}_{2}$ and $70 \% \mathrm{~N}_{2} \mathrm{O}$. The head was again enclosed in the cranial blanket and a brain probe reinserted into the striatum. Brain temperature was gradually cooled without regulating core temperature; the percentage of halothane used to maintain anesthesia was periodically reduced by $0.5 \%$, from $2 \%$ down to $0.5 \%$. Once brain temperature reached $30^{\circ} \mathrm{C}(\sim 20 \mathrm{~min})$, anesthesia was discontinued for $2 \mathrm{~min}$ and the temperature probe was removed. Animals were killed by decapitation and the brain was quickly removed from the skull, placed on ice-cold filter paper, and bisected. The hemisphere used for brain temperature monitoring was reserved for histology (see below) and hippocampal slices were prepared from the other. Briefly, the hippocampus was dissected free, and transverse sections (500 $\mu \mathrm{m}$ ) from the middle half of the hippocampus (along the septotempora axis) were obtained with a tissue chopper and transferred to a holding chamber containing modified artificial ccrcbrospinal fluid (ACSF) consisting of (mmol/liter) sucrose, $215.8 ; \mathrm{KCl}, 3.5 ; \mathrm{CaCl}_{2}, 2.0 ; \mathrm{NaHCO}_{3}$, $25.0 ; \mathrm{NaHPO}_{4}, 1.2 ; \mathrm{MgCl}_{2}, 1.3$; glucose, 11.0 ; bubbled with $95 \% \mathrm{O}_{2} /$ $5 \% \mathrm{CO}_{2}(\mathrm{pH} 7.3-7.4)$. Slices were incubated at room temperature in modified ACSF for $15 \mathrm{~min}$, and subsequently in normal ACSF containing (mmol/liter) $\mathrm{NaCl}, 126.0 ; \mathrm{KCl}, 3.5 ; \mathrm{CaCl}_{2}, 2.0 ; \mathrm{NaHCO}_{3}, 25.0$; $\mathrm{NaHPO}_{4}, 1.2 ; \mathrm{MgCl}, 1.3 ;$ glucose, 11.0 ; saturated with $95 \% \mathrm{O}_{2} / 5 \% \mathrm{CO}_{2}$ (pH 7.3-7.4) for at least $1 \mathrm{hr}$ prior to experimentation. 
Table 1. Brain, skull and rectal temperatures $\left({ }^{\circ} \mathrm{C}\right)$ recorded at the start of occlusion (S.O.), during ischemia, and in the postischemic period following surgery

\begin{tabular}{|c|c|c|c|c|c|c|c|c|c|c|}
\hline \multirow{2}{*}{\multicolumn{2}{|c|}{ S.O. }} & \multicolumn{5}{|c|}{ Ischemia (min) } & \multicolumn{4}{|c|}{ Postischemia (min) } \\
\hline & & 1 & 2 & 3 & 4 & 5 & 30 & 60 & 120 & 180 \\
\hline \multicolumn{11}{|c|}{ Sham-operated } \\
\hline \multirow[t]{2}{*}{ Brain } & 36.9 & 36.9 & 36.9 & 36.9 & 37.0 & 37.0 & 38.3 & 37.9 & 37.8 & 37.4 \\
\hline & \pm 0.6 & \pm 0.4 & \pm 0.3 & \pm 0.3 & \pm 0.2 & \pm 0.2 & \pm 0.4 & \pm 0.2 & \pm 0.4 & \pm 0.6 \\
\hline \multirow[t]{2}{*}{ Skull } & 37.0 & 37.0 & 37.1 & 37.3 & 37.2 & 37.1 & - & - & - & - \\
\hline & \pm 0.6 & \pm 0.8 & \pm 0.6 & \pm 0.5 & \pm 0.7 & \pm 0.9 & & & & \\
\hline \multirow[t]{2}{*}{ Rectal } & 37.9 & 37.8 & 37.8 & 37.8 & 37.8 & 37.8 & 36.8 & 36.5 & - & - \\
\hline & \pm 0.2 & \pm 0.2 & \pm 0.2 & \pm 0.3 & \pm 0.3 & \pm 0.3 & \pm 0.5 & \pm 0.6 & & \\
\hline \multicolumn{11}{|c|}{5 min occlusion: normothermic brain temperature } \\
\hline \multirow[t]{2}{*}{ Brain } & 37.1 & 36.8 & 36.5 & 36.4 & 36.3 & 36.2 & 38.4 & 37.6 & 38.8 & $38.7^{*}$ \\
\hline & \pm 0.1 & \pm 0.4 & \pm 0.6 & \pm 0.7 & \pm 0.7 & \pm 0.5 & \pm 0.4 & \pm 0.5 & \pm 0.8 & \pm 0.6 \\
\hline \multirow[t]{2}{*}{ Skull } & 37.3 & 37.2 & 37.2 & 37.2 & 37.2 & 37.2 & - & - & - & - \\
\hline & \pm 0.5 & \pm 0.8 & \pm 1.0 & \pm 1.0 & \pm 0.9 & \pm 0.9 & & & & \\
\hline \multirow[t]{2}{*}{ Rectal } & 38.0 & 38.0 & 38.0 & 38.0 & 38.0 & 38.0 & 37.3 & 36.0 & - & - \\
\hline & \pm 0.3 & \pm 0.3 & \pm 0.3 & \pm 0.3 & \pm 0.3 & \pm 0.2 & \pm 0.7 & \pm 0.7 & & \\
\hline \multicolumn{11}{|c|}{5 min occlusion: intraischemic brain hypothermia } \\
\hline \multirow[t]{2}{*}{ Brain } & 37.0 & $34.7^{*}$ & $32.5^{* *}$ & $30.7^{* *}$ & $29.6 * *$ & $29.4^{* *}$ & 38.9 & 38.3 & 38.4 & 38.2 \\
\hline & \pm 0.3 & \pm 0.7 & \pm 0.8 & \pm 0.8 & \pm 0.9 & \pm 0.7 & \pm 0.7 & \pm 0.6 & \pm 0.6 & \pm 0.4 \\
\hline \multirow[t]{2}{*}{ Skull } & 37.2 & $31.4 * *$ & $29.8^{* *}$ & $28.7^{* *}$ & $29.6 * *$ & $30.2^{* *}$ & - & - & - & - \\
\hline & \pm 0.7 & \pm 3.5 & \pm 3.4 & \pm 3.3 & \pm 2.0 & \pm 2.3 & & & & \\
\hline \multirow[t]{2}{*}{ Rectal } & 37.9 & 37.9 & 37.9 & 37.8 & 37.8 & 37.7 & $38.3^{*}$ & 37.2 & - & - \\
\hline & \pm 0.3 & \pm 0.3 & \pm 0.2 & \pm 0.2 & \pm 0.2 & \pm 0.3 & \pm 0.9 & \pm 1.2 & & \\
\hline
\end{tabular}

Measurements for sham-operated animals were taken at comparable times relative to the period of anesthesia. Values are the mean \pm SD.

${ }^{*} p<0.05$, post hoc tests (Dunnett $t$ ) compared the sham-operated group to both ischemic groups.

** $p<0.01$.

Extracellular recording of evoked potentials was carried out using a submerged slice preparation in a perfusion chamber at $33-34^{\circ} \mathrm{C}$. The slice was superfused with warmed, oxygenated ACSF at a rate of $2 \mathrm{ml}$ min. Recording electrodes, glass micropipettes (tip diameter $\sim 20 \mu \mathrm{m}$; resistance, $0.5-1.0 \mathrm{M} \Omega$ ) were filled with $2 \mathrm{M} \mathrm{NaCl}$ in $0.5 \%$ agar. Twisted, bipolar tungsten stimulating electrodes (Teflon-coated; tip separation, $125 \mu \mathrm{m}$ ) were used for orthodromic stimulation of perforant path and Schaffer-collateral/commissural fibers with constant-current pulses (100 and $20 \mu \mathrm{sec}$, respectively) delivered at the rate of $0.05 \mathrm{~Hz}$. Recordings were amplified, displayed on an oscilloscope, and digitized for storage and subsequent analysis on a computer. The experimenter was blinded to treatment status while carrying out the electrophysiological investigation. A slice was considered viable if orthodromic stimulation of the perforant path could elicit a population spike in the dentate granule cells; otherwise, it was discarded and no recording in CA1 was attempted.

Histology. The hemisphere retained for histological analysis of CA1 and brain probe placement was fixed by immersion in $10 \%$ phosphatebuffered formalin. The brain tissue was frozen in petroleum ether (cooled with $\mathrm{CO}_{2}$ in acetone), sectioned in the coronal plane at $10 \mu \mathrm{m}$ and stained with cresyl violet. Sectors of the dorsal and ventral CAl pyramidal cell band ( $400 \mu \mathrm{m}$ in length) were rated blindly at three levels posterior to bregma: $1.7 \mathrm{~mm}$ (three dorsal sectors: medial, middle and lateral), $2.2 \mathrm{~mm}$ (four sectors: medial, middle, lateral and ventral), and $2.8 \mathrm{~mm}$ (two sectors: middle and ventral). The percentage of neurons in each sector that appeared viable (i.e., with well-defined nuclei), relative to a normal gerbil hippocampus, were rated using a five-point scale where $0=0-5 \%, 1=6-29 \%, 2=30-59 \%, 3=60-89 \%$, and $4=$ $90-100 \%$. We have previously examined the precision of this rating scalc in rclation to actual cell counts, and found a high correlation $r=$ $0.97, p=0.0001$ ( $n=56$; S. Nurse and D. Corbett, unpublished observations). Assessment of ischemic damage using the above rating scale is also associated with a high degree of interrater reliability.

Statistics. Brain temperature, open field scores and CAl evoked potentials were analyzed using ANOVA. Individual post hoc comparisons were evaluated using Dunnett $t$ test. Histological results were analyzed with the Kruskal-Wallis test. Significance level was initially set at $p<$ 0.05 .

\section{Results}

Intraischemic brain hypothermia was achieved rapidly following onset of ischemia (Table 1). Two minutes into the occlusion, brain temperature in five of seven IBH animals was below $33^{\circ} \mathrm{C}$, and after $3 \mathrm{~min}$ four of seven animals had reached $30^{\circ} \mathrm{C}$. Skull temperature responded even more rapidly to the induced hypothermia, since it was in closer proximity to the cooling source. This temperature gradient pattern was reversed in the NBT group. In this group, the striatal temperature displayed a slight, nonsignificant decrease during the occlusion while the temperature at the skull, being closer to the heating source, remained virtually unchanged (Table 1 ). The mean occlusion temperature (brain) for the IBH group was $31.4^{\circ} \mathrm{C} \pm 2.2 \mathrm{SD}$ compared to $36.5^{\circ} \mathrm{C} \pm 0.6 \mathrm{SD}$ for the NBT group.

In the early postischemic period following anesthesia, all groups (including SHAM) exhibited a period of hyperthermia (Fig. 1). The IBH group displayed the greatest degree of hyperthermia, which peaked at $39.1^{\circ} \mathrm{C} \pm 0.3 \mathrm{SD} 35 \mathrm{~min}$ after ischemia, and was significantly higher than both SHAM and NBT groups $\left(t_{10}\right.$ $=4.9$ and $t_{12}=3.8$, respectively; $p<0.01$ ). This difference was also reflected in the rectal temperatures measured at $30 \mathrm{~min}$ postischemia (see Table 1). The peak brain temperature during this early postischemic period in the NBT group of $38.5^{\circ} \mathrm{C} \pm$ $0.3 \mathrm{SD}$ (also $35 \mathrm{~min}$ postocclusion) only just reached significance compared to sham-operated controls $\left(t_{10}=2.3, p=0.046\right)$. A secondary rise in brain temperature began approximately 90 120 min postocclusion in the NBT and IBH groups. At this time sham-operated animals were approaching the range of normal brain temperature recorded $2 \mathrm{~d}$ prior to surgery, $37.4^{\circ} \mathrm{C} \pm$ $0.4 \mathrm{SD}$. The secondary temperature rise observed in the ische- 


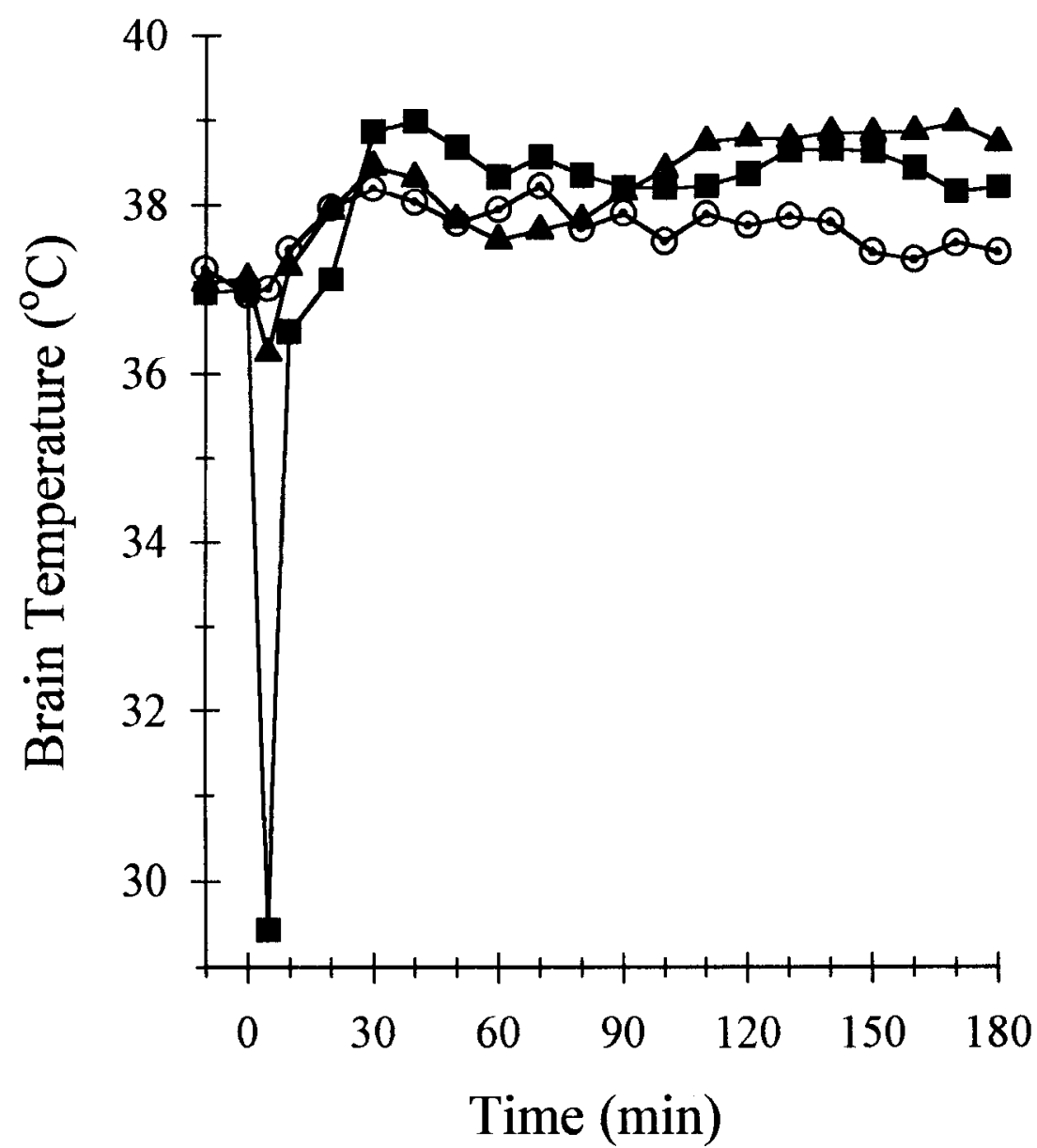

Figure 1. Brain temperature recorded during ischemia/sham operations $(-10$ min to $\sim 10-15 \mathrm{~min}$ ), and then following surgery in unanesthetized animals. Time 0 indicates the initiation of ischemia, group temperaturcs at the end of occlusion are indicated $5 \mathrm{~min}$ after ischemia onset. All values are group means; for clarity the variance has not been indicated but the SDs ranged from $0.05^{\circ} \mathrm{C}$ to $0.9^{\circ} \mathrm{C}$. For detailed temperature profiles during occlusion see $\mathrm{Ta}$ ble 1. Open circles, SHAM $(n=5)$; solid triangles, NBT group $(n=7)$; solid squares, IBH group $(n=7)$. mic groups appeared to be the result of an acute phase of locomotor hyperactivity that was less pronounced and recovered faster in the animals treated with intraischemic hypothermia. We did not see any evidence of seizures during the postischemic observation period, and there were no fatalities in this study.

Sham-operated animals displayed normal levels of cxploration during the first exposure to the open field, which declined on subsequent test days (Fig. 2). In contrast, the animals occluded at normothermia exhibited heightened levels of activity during all test sessions, with little or no within session habituation to the environment. However, in animals subjected to hypothermia no impairment was noted, except for a tendency on day 3 to have slightly elevated levels of exploration relative to controls. All animals appeared healthy on each test day, and there were no group differences in initial weight or in weight assessed 7, 14, and $21 \mathrm{~d}$ after ischemia (data not shown).

Evoked responses of CA1 pyramidal cells to orthodromic stimulation were measured in all 20 animals, 3 weeks postischemia. Field excitatory postsynaptic potentials (fEPSPs) from 55 hippocampal slices were recorded in stratum radiatum following stimulation of Schaffer-collateral/commissural fibers. Not surprisingly, in slices taken from animals in the NBT group there was a dramatic reduction of the $\mathrm{CA} 1$ response, although a presynaptic fiber volley was often recorded (Fig. 3). The reduction in the amplitude of the response was associated with a decrease in the slope and area of the fEPSPs (Fig. 4). We also found a significant change in the latency of the response, starting an average of $2.3 \mathrm{msec}$ following stimulation compared to 1.72 msec in sham-operated controls. However, in slices taken from animals treated with intraischemic hypothermia we recorded field potentials in CAl that were indistinguishable from shams.

Histological assessment of CAl confirmed that there was substantial cell loss from dorsal CAl in the NBT group at all three rostrocaudal levels (Fig. 5), while intraischemic hypothermia provided remarkable protection against the $5 \mathrm{~min}$ occlusion, as previously suggested by the functional measures. In both ischemic groups we observed greater neuronal injury at the most rostral level assessed $(-1.7 \mathrm{~mm})$, and cell loss in dorsal CA1 tended to be most severe in the medial sector (near subiculum) compared to the middle and lateral sectors. There was no significant cell loss in ventral CA1.

The mean brain temperatures during occlusion, of both ischemic groups combined, accurately predicted histological outcome 3 weeks later (level $-1.7 \mathrm{~mm} ; r=0.98, p=0.0001$ ). Within the IBH group alone this still holds true, animals with higher mean occlusion temperatures (probably resulting from a slower rate of cooling) had a greater degree of CAl damage ( $r=0.78$, $p=0.04$ ), but occlusion temperatures measured at the skull were not predictive of eventual cell loss $(r=0.07, p=0.88)$. Within the NBT group, there was no relationship between temperature during ischemia and histological outcome (most likely as a result of the strict temperature maintenance throughout occlusion). For this group, variability in CA1 damage scores was attributable to the brain temperature during the first $90 \mathrm{~min}$ of reperfusion ( $r=0.77, p=0.04$ ).

Each of the functional measures used in this study, assessment 


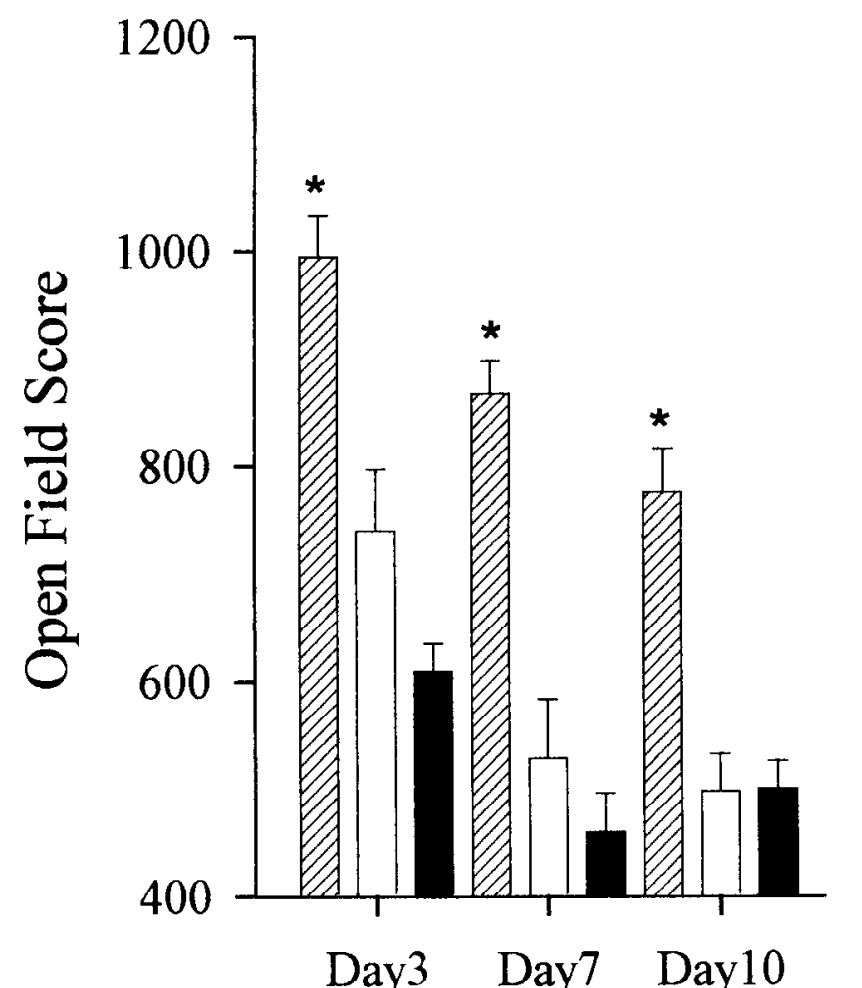

Figure 2. Fxploratory activity in a novel open field, on each of the three postischemic test days. Solid bars, SHAM $(n=6)$; hatched bars, NBT $(n=7)$; open bars, IBH $(n=7)$. All values are the group means \pm SEM. There was a significant treatment effect $\left(F_{2,17}=37.812, p<\right.$ $0.0001)$ as a result of the heightened activity exhibited by the NBT group on all test days, which was significantly different from shamoperated controls $\left(^{*}, p<0.01\right.$, Dunnett $\left.t\right)$.

of open field activity and fEPSPs measured in stratum radiatum, correlated highly with the extent of CAl cell loss (see Table 2).

\section{Discussion}

This study demonstrates that intraischemic hypothermia provides near complete protection of CAl pyramidal cells from an episode of cerebral ischemia. Not only did we find that there was no significant CA1 cell loss 3 weeks postocclusion if intraischemic hypothermia was administered, but also, typical behavioral impairments associated with ischemic injury were absent and CAl synaptic transmission was preserved. While other experiments have utilized behavioral tests in conjunction with histological assessment to demonstrate both functional and morphological protection, this study is unique in that electrophysiological measures were combined with behavioral and histological evaluations of CA1 integrity. Functional mcasures of assessment can verify whether a "protective treatment" is providing true protection. It is possible that some drug therapies that appear to be protective histologically may fail to yield functional protection because cells are in a transitional state from which they may or may not recover.

Open field testing in this study was carried out from 3 to 10 $\mathrm{d}$ postischemia. If hypothermia had not preserved normal function, then testing during this time period would be more likely to detect an impairment since behavioral tests should be more sensitive before any substantial recovery of function has taken place. We did not find any significant difference in exploratory
A
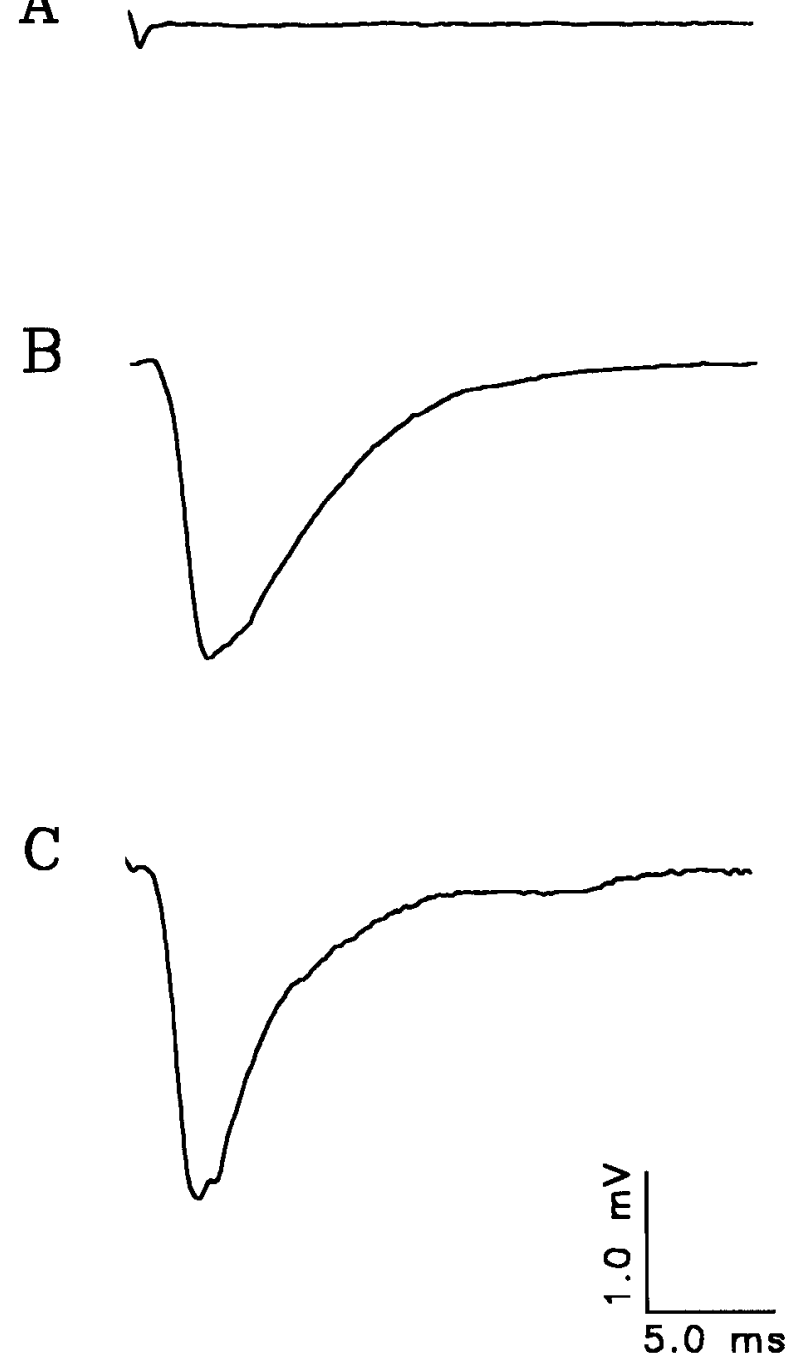

Figure 3. Representative EPSPs recorded in the CA1 dendritic field from each treatment group: $A$, NBT; $B$, IBH; $C$, SHAM. Field potentials were similar in both the IBH and SHAM groups. However, orthodromic stimulation of CAl in a hippocampal slice from the NBT group only elicited a fiber volley, which represents multiple action potentials in the presynaptic axons.

activity between IBH and SHAM groups exposed to a novel open field, even during the first week postischemia. However, there was a nonsignificant tendency for the IBH group to display higher levels of exploratory activity than the SHAM group 3 and $7 \mathrm{~d}$ postischemia (Fig. 2), whereas on day 10 full recovery had taken place. The NBT group displayed very high activity levels, and a much slower rate of habituation to the environment over all three test sessions. These results suggest that it is important to conduct behavioral tests (depending on task complexity) within the first weeks after occlusion in order to detect functional impairments of compromised systems at risk for subsequent insults. This would be essential in cases of partial protection produced by any type of therapeutic intervention.

It has previously been shown that the open field task is sensitive to hippocampal damage resulting from forebrain ischemia, and impairments are unrelated to cell loss in other brain regions such as striatum (Mileson and Schwartz, 1991). Our findings imply that hippocampal function has been spared when 
hypothermia was administered during a $5 \mathrm{~min}$ ischemic cpisode. Green et al. (1992) have also suggested that intraischemic hypothermia preserves hippocampal function (using a Morris water maze task). However, their functional measure was not predictive of the histological outcome. In this study both open field exploration and the electrophysiological competence of CA1 pyramidal cells was predictive of dorsal CA1 cell ratings.

Previous studies (Buzsaki et al., 1989; Urban et al., 1989, 1990; Jensen et al., 1991; Kirino et al., 1992) have utilized electrophysiological measures to study changes in neuronal transmission and to monitor the progression of cell death during the initial hours and days after an ischemic event. To the best of our knowledge this is the first report using extracellular recording techniques several weeks after occlusion to demonstrate that a putative anti-ischemic therapy has preserved normal synaptic function in the CA1 region. Measuring the physiological properties of CAl neurons has the advantage that recovery of function and compensatory mechanisms that help reduce behavioral deficits several weeks after ischemia do not interfere with the direct functional assessment of CA1. Field responses recorded in stratum radiatum from the IBH group were similar to those from SHAM controls on measures of amplitude, area and slope. Again, as seen with early behavioral testing, there was a slight trend for the size of the CA1 field potentials to be reduced in the IBH group versus SHAM controls (see Fig. 4A). This slight reduction in field potential size most likely reflects a small loss of CA1 neurons in some animals, which is consistent with the morphological outcome. Within the NBT group, there was a noticeable variation in response depending on where the slice had been taken along the septotemporal axis of the hippocampus. Field responses in the majority of NBT slices were severely attenuated or completely absent; however, some slices from the more ventral aspect of the hippocampus had much larger fEPSPs that in a few cases were near normal in size. These differences between dorsal and ventral CA1 were also observed in the histological assessment.

The single most important determinant of CAl injury in this study was the brain temperature during occlusion. This was most obvious within the IBH group because of a greater range in intraischemic brain temperatures. When CA1 ratings for this group were compared to minute-by-minute brain temperatures throughout the period of ischemia, we found that only one time point was predictive of histological outcome. The critical factor that determined whether an animal would have total or near total protection was the brain temperature at $3 \mathrm{~min}$ into the occlusion $(r=0.87, p=0.01)$. Both in vitro and in vivo ischemia models have independently shown that 2.5-3 min appears to be a threshold point below which no permanent injury occurs, but beyond this time CAl neurons are irreversibly damaged (Nowak et al., 1985; Kato et al., 1989; Raley and Lipton, 1990; Andou et al., 1992). Within the IBH group, we found the least protection $(-1.7 \mathrm{~mm}$ : rating scores $8 / 12$ and 9/12) in animals that had the highest brain temperatures following $3 \mathrm{~min}$ of ischemia $\left(31.9^{\circ} \mathrm{C}\right.$ and $31.8^{\circ} \mathrm{C}$, respectively), while the two animals with complete protection $(-1.7 \mathrm{~mm}$ : rating scores $12 / 12)$ had the lowest brain temperatures at this time, $30.1^{\circ} \mathrm{C}$ and $30.0^{\circ} \mathrm{C}$. Thus, complete protection against a $5 \mathrm{~min}$ occlusion could be obtained if the brain temperature was cooled to a sufficient level before the $3 \mathrm{~min}$ threshold point was crossed. Interestingly, Raley and Lipton (1990) have shown that hippocampal slices subjected to in vitro "ischemia" for 2 min will quickly recover protein synthesis to normal levels, whereas ischemia of $5 \mathrm{~min}$
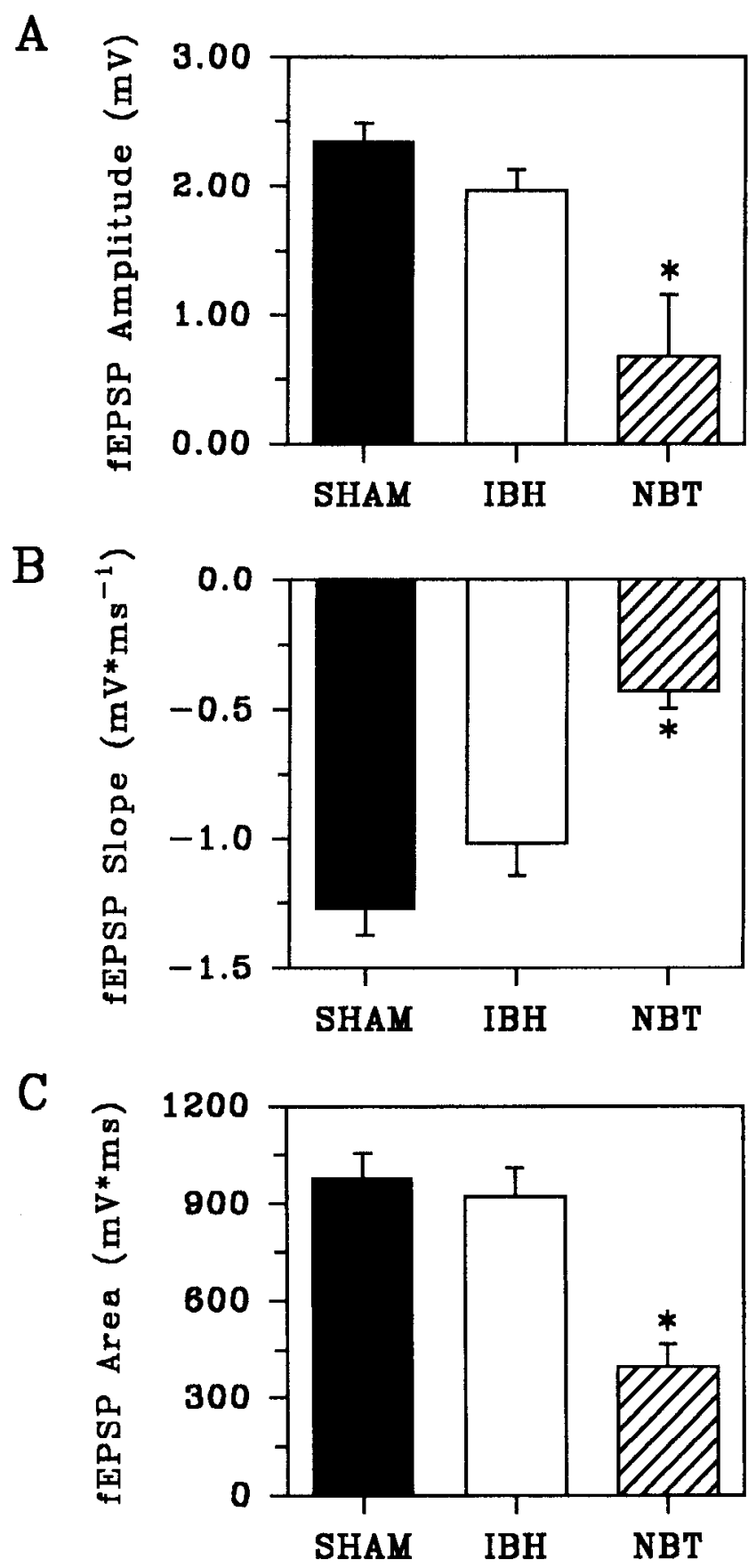

Figure 4. Measurements of CA1 fEPSPs recorded in stratum radiatum from 55 hippocampal slices (SHAM, $n=16$; NBT, $n=19$; IBH, $n=$ 20) 3 weeks postischemia. Fach figure illustrates the group means \pm SEM. $A$, fEPSP amplitude; $B$, fEPSP slope; $C$, fEPSP area. ANOVA indicated a significant treatment effect for all three measures $\left(F_{2,52}=\right.$ $38.97,17.701$, and 17.198 , respectively; $p=0.0001$ ) resulting from a reduction in the size of field potentials recorded from the NBT group $\left({ }^{*}, p<0.01\right.$, Dunnett $\left.t\right)$.

duration will result in an extended period of protein synthesis inhibition. Intraischemic hypothermia, in vivo, may exert its protective action by preventing the pathogenesis that occurs after 2.5-3 min of ischemia, thus allowing recovery of protein synthesis and normal neuronal function (see Widmann et al., 1993). In addition to the importance of intraischemic brain temperature, we also observed that postischemic temperature 


\section{Dorsal CA1}

$-1.7 \mathrm{~mm}$

$-2.2 \mathrm{~mm}$

$-2.8 \mathrm{~mm}$

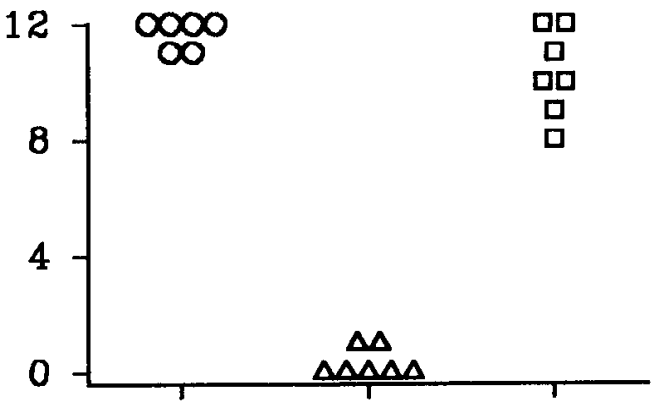

Ventral CA1
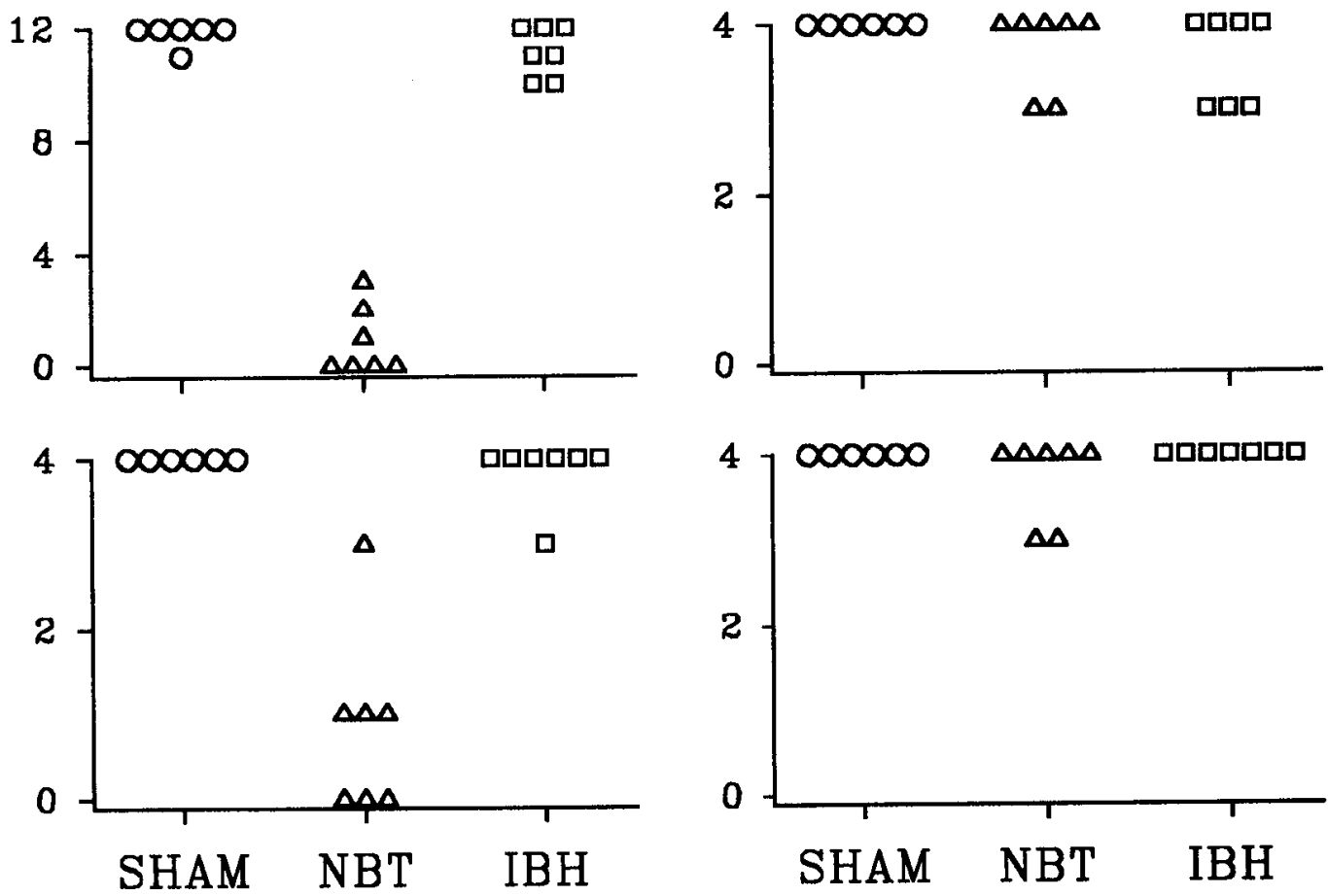

Figure 5. Histological assessment of CAl at three rostrocaudal levels located posterior to bregma. Plotted points represent the individual scores for each animal. Circles, SHAM $(n=6)$; triangles, NBT group $(n=7)$; squares, IBH group $(n=7)$. Ratings of dorsal CA1 are indicated on the left and ventral CA1 on the right. Evaluation of dorsal CAl at the most rostral levels $(-1.7 \mathrm{~mm}$ and $-2.2 \mathrm{~mm})$ is based on the summed ratings from three sectors (maximum rating $=12$ ). One sector was rated for the assessment of dorsal CAl at the most caudal level $(-2.8 \mathrm{~mm})$ and both ventral levels (maximum score $=4)$. There was a significant treatment effect at all dorsal levels examined $(H=14.27,13.80$, and 12.81 for $-1.7 \mathrm{~mm}$, $-2.2 \mathrm{~mm}$, and $-2.8 \mathrm{~mm}$, respectively; $p<0.01$, Kruskal-Wallis test) as a result of the extensive cell loss from CA1 observed in NBT animals subjected to ischemia at normothermia.

can influence outcome. As seen in the NBT group, small variations in brain temperature during the first 90 min of reperfusion had significant effects on both functional and histological outcome.

A question raised by the present data is whether intraischemic hypothermia provides permanent neuroprotection. Some of the animals treated with intraischemic hypothermia may not have complete protection as evidenced by the observed trend for this group to display small, nonsignificant deficits in comparison to sham-operated controls on all three assessments. However, these slight differences were apparent within the first week after ischemia and were not exacerbated over time as would be expected if cell loss was continuing beyond $7 \mathrm{~d}$ postocclusion. In addition to histological outcome, the electrophysiological recordings made 3 weeks postischemia indicated that synaptic transmission was normal, which is suggestive of permanent protection of CA1 neurons. Consistent with our findings, Dietrich et al. (1993) have shown that when the brain is cooled to $30^{\circ} \mathrm{C}$ during the period of ischemia, histological protection is still observed 2 months later. Permanent functional as well as histological protection, resulting from hypothermic intervention during ischemia, has also been demonstrated by Green et al. (1992).

In this study, open field behavior and extracellular field recordings evoked in the CAl dendritic field both predicted histological outcome. The functional measures correlated significantly with each other and with dorsal CAl ratings. It would seem that any one of these measures alone could adequately determine outcome following ischemia. However, we believe that only when a treatment has provided true, permanent protection will there be such a consistent relationship between each 
Table 2. Correlation matrix

\begin{tabular}{|c|c|c|c|c|c|c|c|c|c|}
\hline & \multicolumn{3}{|c|}{ Open field behavior } & \multicolumn{3}{|c|}{ fEPSPs, stratum radiatum } & \multicolumn{3}{|c|}{ Histological assessment, dorsal CA1 } \\
\hline & Day 3 & Day 7 & Day 10 & Amplitude & Slope & Area & $-1.7 \mathrm{~mm}$ & $-2.2 \mathrm{~mm}$ & $-2.8 \mathrm{~mm}$ \\
\hline \multicolumn{10}{|l|}{ Behavior } \\
\hline \multicolumn{10}{|l|}{ Day 3} \\
\hline Day 7 & 0.82 & & & & & & & & \\
\hline Day 10 & 0.70 & 0.90 & & & & & & & \\
\hline \multicolumn{10}{|l|}{ fEPSPs } \\
\hline Amplitude & -0.81 & -0.76 & -0.76 & & & & & & \\
\hline Slope & 0.73 & 0.66 & 0.66 & -0.93 & & & & & \\
\hline Area & -0.68 & -0.70 & -0.77 & 0.87 & -0.71 & & & & \\
\hline \multicolumn{10}{|l|}{ CA1 rating } \\
\hline$-1.7 \mathrm{~mm}$ & -0.84 & -0.90 & -0.87 & 0.88 & -0.76 & 0.82 & & & \\
\hline$-2.2 \mathrm{~mm}$ & -0.83 & -0.89 & -0.88 & 0.86 & -0.76 & 0.79 & 0.98 & & \\
\hline$-2.8 \mathrm{~mm}$ & -0.78 & -0.85 & -0.82 & 0.76 & -0.66 & 0.72 & 0.93 & 0.96 & \\
\hline
\end{tabular}

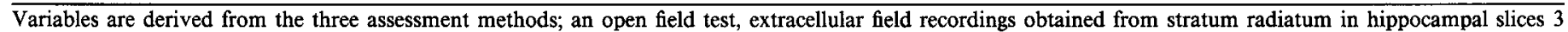

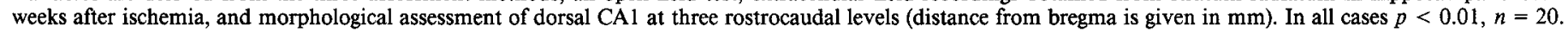

of the measures used in this study. For example, other treatments such as drug therapy or postischemic hypothermia may not provide long-lasting protection, but only delay cell death (Dietrich et al., 1993; Colbourne and Corbett, in press). In view of these considerations it would seem advantageous to combine histopathological assessment with functional assessments using long survival times (e.g., at least several weeks). This approach will provide a more accurate indication of the viability of hippocampal neurons.

\section{References}

Andou Y, Mitani A, Masuda S, Arai T, Kataoka K (1992) Re-evaluation of ischemia-induced neuronal damage in hippocampal regions in the normothermic gerbil. Acta Neuropathol (Berl) 85:10-14.

Auer RN, Jensen ML, Whishaw IQ (1989) Neurobehavioral deficit duc to ischemic brain damage limited to half of the CA1 sector of the hippocampus. J Neurosci 9:1641-1647.

Babcock AM, Baker DA, Lovec R (1993) Locomotor-activity in the ischemic gerbil. Brain Res 625:351-354.

Buchan A (1992) Advances in cerebral ischemia: experimental approaches. Neurol Clin 10:49-61.

Busto R, Dietrich WD, Globus MY-T, Valdes I, Scheinberg P, Ginsberg MD (1987) Small differences in intraischemic brain temperature critically determine the extent of ischemic neuronal injury. J Cereb Blood Flow Metab 7:729-738.

Buzsaki G, Freund TF, Bayardo F, Somogyi P (1989) Ischemia-induced changes in the electrical activity of the hippocampus. Exp Brain Res 78:268-278.

Choi DW (1985) Glutamate neurotoxicity in cortical cell culture is calcium dependent. Neurosci Lett 58:293-297.

Chopp M, Knight R, Tidwell CD, Helpern JA, Brown E, Welch KMA (1989) The metabolic effects of mild hypothermia on global cerebral ischemia and recirculation in the cat: comparison to normothermia and hyperthermia. J Cereb Blood Flow Metab 9:141-148.

Colbourne F, Corbett D (in press) Delayed and prolonged postischemic hypothermia is neuroprotective in the gerbil. Brain Res, in press.

Colbourne F, Nurse SM, Corbett D (1993) Temperature changes associated with forebrain ischemia in the gerbil. Brain Res 602:264 267.

Corbett D, Evans SJ, Nurse SM (1992) Impaired acquisition of the Morris water maze following global ischemic damage in the gerbil. Neuroreport 3:204-206.

Dietrich WD, Busto R, Alonso O, Globus MY-T, Ginsberg MD (1993) Intraischemic but not postischemic brain hypothermia protects chronically following global forebrain ischemia in rats. J Cereb Blood Flow Metab 13:541-549.
Gerhardt SC, Boast CA (1988) Motor activity changes following cerebral ischemia in gerbils are correlated with the degree of neuronal degeneration in hippocampus. Behav Neurosci 102:301-303.

Green EJ, Dietrich WD, van Dijk F, Busto R, Markgraf CG, McCabe PM, Ginsberg MD, Schneiderman N (1992) Protective effects of brain hypothermia on behavior and histopathology following global cerebral ischemia in rats. Brain Res 580:197-204.

Horn M, Schlote W (1992) Delayed neuronal death and delayed neuronal recovery in the human brain following global ischemia. Acta Neuropathol (Berl) 85:79-87.

Imamura L, Ohta H, Ni X-H, Matsumoto K, Watanabe H (1991) Effects of transient cerebral ischemia in gerbils on working memory performance in the delayed nonmatching to position task using a T-maze. Jpn J Pharmacol 57:601-608.

Iwai T, Niwa M, Yamada H, Nozaki M, Tsurumi K (1993) Hypothermic prevention of the hippocampal damage following ischemia in Mongolian gerbils: comparison between intraischemic and brief postischemic hypothermia. Life Sci 52:1031-1038.

Jaspers RMA, Block F, Ileim C, Sontag K-II (1990) Spatial learning is affected by transient occlusion of common carotid arteries (2VO): comparison of behavioural and histopathological changes after ' $2 \mathrm{VO}$ ' and 'four-vessel-occlusion' in rats. Neurosci Lett 117:149-153.

Jensen MS, Lambert JDC, Johansen FF (1991) Electrophysiological recordings from rat hippocampus slices following in vivo brain ischemia. Brain Res 554:166-175.

Kaplan TM, Lasner TM, Nadler JV, Crain BJ (1989) Lesions of excitatory pathways reduce hippocampal cell death after transient forebrain ischemia in the gerbil. Acta Neuropathol (Berl) 78:283-290.

Kato H, Kogure K, Nakano S (1989) Neuronal damage following brief ischemia in the gerbil. Brain Res 479:366-370.

Katoh A, Ishibashi C, Shiomi T, Takahara Y, Eigyo M (1992) Ischemia-induced irreversible deficit of memory function in gerbils. Brain Res 577:57-63.

Kirino T (1982) Delayed neuronal death in the gerbil hippocampus following ischemia. Brain Res 237:57-69.

Kirino T, Robinson HPC, Miwa A, Tamura A, Kawai N (1992) Disturbance of membrane function preceding ischemic delayed neuronal death in the gerbil hippocampus. J Cereb Blood Flow Metab 12:408417.

Mileson BE, Schwartz RD (1991) The use of locomotor activity as a behavioral screen for neuronal damage following transient forebrain ischemia in gerbils. Neurosci Lett 128:71-76.

Minamisawa H, Nordstrom CH, Smith M-L, Siesjo BK (1990a) The influence of mild body and brain hypothermia on ischemic brain damage. J Cereb Blood Flow Metab 10:365-374.

Minamisawa H, Smith M-L, Siesjo BK (1990b) The effects of mild hyperthermia and hypothermia on brain damage following 5, 10 and 15 minutes of forebrain ischemia. Ann Neurol 28:26-33.

Nowak TS, Fried RL, Lust WD, Passonneau JV (1985) Changes in 
brain energy metabolism and protein synthesis following transient bilateral ischemia in the gerbil. J Neurochem 44:487-494.

Pulsinelli WA, Brierly JB, Plum F (1982) Temporal profile of neuronal damage in a model of transient forebrain ischemia. Ann Neurol 11: 491-499.

Raley KM, Lipton P (1990) NMDA receptor activation accelerates ischemic energy depletion in the hippocampal slice and the demonstration of a threshold for ischemic damage to protein synthesis. Neurosci Lett 110:118-123.

Siesjo BK, Bengtsson F (1989) Calcium fluxes, calcium antagonists and calcium-related pathology in brain ischemia, hypoglycemia and spreading depression. J Cereb Blood Flow Metab 9:127-140.

Tsubokawa H, Oguro K, Robinson HPC, Masuzawa T, Kirino T, Kawai $\mathrm{N}$ (1992) Abnormal $\mathrm{Ca}^{2+}$ homeostasis before cell death revealed by whole cell recording of ischemic CA1 hippocampal neurons. Neurosci 49:807-817.

Urban L, Neill KH, Crain BJ, Nadler JV, Somjen GG (1989) Postischemic synaptic physiology in area CAl of the gerbil hippocampus studied in vitro. J Neurosci 9:3966-3975.

Urban L, Neill KH, Crain BJ, Nadler JV, Somjen GG (1990) Effects of transient forebrain ischemia in area CAl of the gerbil hippocampus: an in vitro study. Adv Exp Med Biol 268:491-500.
Wang D, Corbett D (1990) Cerebral ischemia, locomotor activity and spatial mapping. Brain Res 533:78-82.

Warner MA, Nadler JV, Crain BJ (1990) Effects of NMDA receptor antagonists and body temperature in the gerbil carotid occlusion model of transient forebrain ischemia. In: Current and future trends in anticonvulsant, anxiety, and stroke therapy, pp 409-414. New York: Wiley-Liss.

Welsh FA, Sims RE, Harris VA (1990) Mild hypothermia prevents ischemic injury in gerbil hippocampus. J Cereb Blood Flow Metab 10:557-563.

Widmann R, Miyazawa T, Hossmann K-A (1993) Protective effect of hypothermia on hippocampal injury after 30 minutes of forebrain ischemia in rats is mediated by postischemic recovery of protein synthesis. J Neurochem 61:200-209.

Zola-Morgan S, Squire LR, Amaral DG (1986) Human amnesia and the medial temporal region: enduring memory impairment following a bilateral lesion limited to field CAl of the hippocampus. J Neurosci 6:2950-2967.

Zola-Morgan S, Squire LR, Rempel NL, Clower RP, Amaral DG (1992) Enduring memory impairment in monkeys after ischemic damage to the hippocampus. J Neurosci 12:2582-2596. 